\title{
A developmental analysis of the relationship between response strength and punishment
}

\author{
A. JOHN ERNST and RANDALL W. YEE \\ Washington State University, Pullman, Washington 99163
}

\begin{abstract}
Two levels of training (100 vs. 500 trials) and two ages of rats (young and adult) were used in a developmental analysis of the relationship between response strength and the effects of punishment. The apparatus was a $\mathrm{Y}$ maze with three discriminably different arms. After 100 or 500 reinforced trials, subjects were shocked each time they responded in one arm. The recovery sessions followed the punishment session. Results from the punishment day indicated that: (a) young rats received a greater amount of shock, and (b) additional training increased the amount of shock received by the young but decreased it in the adults. The recovery data showed that: (a) the suppressive effects of punishment were greater for the adults than for the young, and (b) the recovery scores were not influenced by degree of overtraining. The Age by Overtraining interaction suggested that the relationship between response strength and punishment is age dependent. The age differences found with the amount-of-shock and recovery measures provided additional support for the position that younger rats are less competent than adult rats in inhibiting responses.
\end{abstract}

This study used punishment to investigate the relationship between age and response strength in order to deal with problems posed in both previous developmental punishment research and response-strength punishment research. Although developmental studies of learning have shown that punishment has less effect on young than on adult rats, this difference may have resulted from greater response strength in the young prior to punishment.

This greater suppressive effect of punishment on older rats has been found with the passive avoidance procedure (Feigley \& Spear, 1970; Riccio \& Schulenberg, 1969; Schulenberg, Riccio, \& Stikes, 1971), with the punishment of a positively reinforced response (Ernst, 1972), and with the punishment of an active avoidance response (Riccio \& Marrazo, 1972). Although this age difference has been interpreted as supporting the position that younger rats are less capable in a task that requires the inhibition of a response, it is possible that these age differences resulted from the young having stronger responses that were less affected by punishment. For example, one of the most commonly used developmental paradigms has been the passive avoidance procedure in which the experimenter has no control over response strength prior to punishment. Additional support for this concern over response strength comes from a study by Ernst (1972) in which there was some indication that the age differences found with the number-of-shocks-to-suppression measure may have been related to response strength.

This research was supported in part by Grant 13B-2474-0490 from the Washington State University Research Committee. We wish to acknowledge the assistance of Barbara Homrich and Norm Gustavson with the testing of subjects.

Requests for reprints should be sent to A. John Ernst, Department of Psychology, Washington State University, Pullman, Washington 99163.
Although the problem of response strength has been acknowledged by other developmental researchers (Campbell, Riccio, \& Rohrbaugh, 1971; Riccio \& Marrazo, 1972), there has been no systematic developmental analysis of the relationship between response strength and punishment. Since the understanding of this relationship may be important for interpreting previous developmental punishment research, the present study was undertaken.

A second purpose of this study was to attempt to resolve an apparent controversy in the research that has focused on the relationship between response strength and punishment. Although a stimulus-response learning theory (e.g., Hull, 1943) might predict that habit strength is an increasing function of the number of reinforced trials and that increased habit strength would increase resistance to punishment, studies with adult rats have typically found that there is a curvilinear relationship between response strength and the effects of punishment; that is, training up to a certain point increases resistance to punishment but overtraining decreases resistance to punishment. This overtraining effect has been found or suggested with runway studies (Karsh, 1962; Miller, 1960) and with operant studies (Born, 1967; Lawson \& Born, 1964). The only punishment study that found an effect consistent with the theoretical prediction was that of Karsh and Williams (1964) with children in which additional training made punishment less effective. Although the experimenters interpreted the difference between their results and the results from the rat studies as reflecting species differences (i.e., rats were more stimulus bound than children), this difference may have been due to developmental differences in the relationship between response strength and punishment. Therefore, the present study attempted to resolve this question by 
examining overtraining and punishment with young and adult rats. If the conflicting results in the previous studies were due to developmental differences, then young rats should show the effect found with children and aduit rats should show the overtraining effect previously found with rats.

In addition to providing a developmental analysis of overtraining and punishment, the present study extends previous research in two respects. The first is in the two dependent measures used. It was thought that the relationship between age, overtraining, and the effects of punishment could be more thoroughly analyzed by using two measures: (1) amount of shock to suppression and (2) sessions to recovery after shock was discontinued. It seemed important to use both since Einst (1972) had found significant developmental differences in the effects of punishment between these two measures.

The use of these two suppression measures also extends the response-strength punishment research in that most of these studies used time-dependent measures such as running speed (Karsh, 1962; Miller, 1960) or latency to first response after punishment (Lawson \& Born, 1964). Only one of the studies that found an overtraining effect used a measure of the amount of shock to suppression (Born, 1967). In addition, none of them used a measure of sessions to recovery after suppression.

The second difference between this study and most of the previous developmental research is that reinforced alternatives were provided to the punished response, thereby allowing suppression to be measured in the context of continuous responding. In the previous passive avoidance research, the suppression measure depended on the nonresponse of the subject. Since previous research had shown that there was an age difference in activity (Moorcroft, Lytle, \& Campbell, 1971), the obtained age difference in suppression in the passive avoidance studies may have been influenced by this factor.

\section{METHOD}

\section{Subjects}

Seventy-six male hooded rats were obtained from the breeding colony at Washington State University. At the time of the shaping session, the young rats were 23 and 31 days old and the adults were 95 to 110 days old. Different ages of young were used so that all the young would be 34 days old for the shock session. The animals were housed in individual cages in the laboratory, and water was available at all times.

\section{Apparatus}

The apparatus was a Y maze with three discriminably different arms. One was black, another white, and a third had alternating 3/4-in. vertical stripes of black and white. Each arm was $15 \times 5 \times 14 \mathrm{in}$. The floor consisted of hardware cloth, except for the last 7 in. at the end of each arm where $1 / 8$-in. stainless steel rods were set at 3/8-in. intervals. A dipper at the end of each arm presented a $25 \%$ sucrose solution. An entry-exit photcell was located 3 in. into each arm, and a dipper photocell was located $1 / 2 \mathrm{in}$. from the end. The breaking of the dipper photobeam raised the ladle (which was normally down), and it stayed up for $3 / 4 \mathrm{sec}$ after a subject started to lick. This function was controlled by using a drinkometer in conjunction with a clock. After the ladle was lowered, it could not be raised a second time until the subject had licked at one of the other two dippers. If the subject raised the ladle but left that arm without licking, the ladle was lowered by the breaking of the entry-exit photobeam. The top of the apparatus was covered with white Plexiglas. A small lamp was mounted in the top, halfway down each arm. White noise was delivered through a speaker mounted in the top at the junction of the three arms. Electric shock was delivered through the dipper ladle to the floor grid by means of a dc constant-current shock source (Lehigh Valley Model 1531). An electronic clock measured the duration of each shock by means of a special electronic circuit. Control of the apparatus was automated.

\section{Procedure}

In general, the procedure involved shaping the rat to lick, giving 2 or 10 sessions in which responding in all three arms was reinforced, using punishment in one arm for one session, and then observing the recovery of the punished response over subsequent sessions in which responding in all arms was again reinforced.

The young were weaned at 20 days of age. Both age groups were handled for $5 \mathrm{~min}$ per day for 3 days prior to the first training session during which they learned to lick sucrose. On the day following the training-to-lick session, the apparatus was put on automatic control for the first regular session. Subjects received one session per day, with 50 reinforcements per session. Subjects were fed daily between 15 to $20 \mathrm{~g}$ of lab chow. This maintained adults at $90 \%-95 \%$ of their ad-lib weight and allowed the young to show an average daily growth of 3 to $4 \mathrm{~g}$. Generally, it took the young about $15-19 \mathrm{~h}$ to consume their daily allotment of food and it took the adults between 9 and $13 \mathrm{~h}$. All subjects were started on their deprivation schedule 3 days prior to the shaping session.

After 2 or 10 regular sessions (100 or 500 reinforcements), shock was introduced. The subjects received a 2 -mA shock in either the black or the white arm. They were shocked each time they licked, and for as long as they were in contact with the ladle. To help insure that subjects would continue to respond in the nonshock arms after punishment was initiated, they were fed $40 \%$ less food on the day prior to the punishment session. The body weight of the young dropped $2 \%$ to $3 \%$ below the level of the last preshock session while the adults lost an additional $5 \%-6 \%$ of their ad-lib weight. The session ended when subjects had either obtained 50 reinforcements after the first shock or had not responded in any of the arms for $20 \mathrm{~min}$.

Following the shock session, the postpunishment or recovery sessions began. During these sessions, reinforcement was available in all three arms. Daily test sessions with 50 reinforcements per session continued until the subjects met the criterion of no suppression (15 or more reinforcements in the shock arm for 3 consecutive days) or had received the maximum number of postshock sessions (50).

Measures were obtained in each arm for the number of times a subject entered the arm and licked (number of reinforcements). The sequence of responding in the three arms was also recorded for the preshock sessions, and session length was recorded for all sessions. During the punishment session, measures of the duration of each shock and of the number of subjects that stopped responding for $20 \mathrm{~min}$ were obtained. The recovery measure was obtained by assigning each subject a score which represented the total number of postshock sessions received before the criterion of no suppression was reached. If a subject did not reach this criterion, he was assigned a score of 50 which was the maximum number of postshock sessions allowed.

The resulting design was a 2 by 2 factorial with two age levels 
(young and adult rats) and two levels of response strength (2 or 10 prepunishment sessions). There were four independent groups, with 19 subjects per group.

\section{RESULTS}

\section{Preshock Sessions}

The adult and young rats had a similar distribution of responses per session in the three arms, the most common consisting of 16,17 , and 17 . Rarely did the number of responses fall below 15 in any arm. Both age groups also showed a similar sequence of responding in the three arms (1-2-3-1-2-3).

When the session-length data were analyzed for the first two sessions, it was found that the young rats took significantly longer than adults to complete these sessions $(\bar{X}=21.9$ vs. $14.6 \mathrm{~min} ; \mathrm{F}=32.8, \mathrm{df}=1 / 74$, $\mathrm{p}<.01)$. There was also a significant decline in session length over the two sessions $(\bar{X}=23.7$ vs. $12.8 \mathrm{~min}$; $\mathrm{F}=128.2, \mathrm{df}=1 / 74, \mathrm{p}<.01)$. The Age by Session interaction was not significant $(\mathrm{F}<1)$.

When the session-length data for the last two preshock sessions were compared (for the two-session subjects these were the same as the first two), the young were still taking significantly longer than the adults $(\overline{\mathrm{X}}=15.2$ vs. $10.6 \mathrm{~min} ; \mathrm{F}=17.3 \mathrm{df}=1 / 72, \mathrm{p}<.01$ ). In addition, subjects in the 2 -session condition took significantly longer than those in the 10-session condition $(\overline{\mathrm{X}}=17.2$ vs. $8.6 \mathrm{~min} ; \mathrm{F}=61.8, \mathrm{df}=1 / 72, \mathrm{p}<.01$ ), and subjects in the 2-session group also showed a greater decline over these sessions than the 10-session group $(\overline{\mathrm{X}}$ drop $=11.8$ vs. $1.7 \mathrm{~min}$; Number of Preshock Sessions by Two

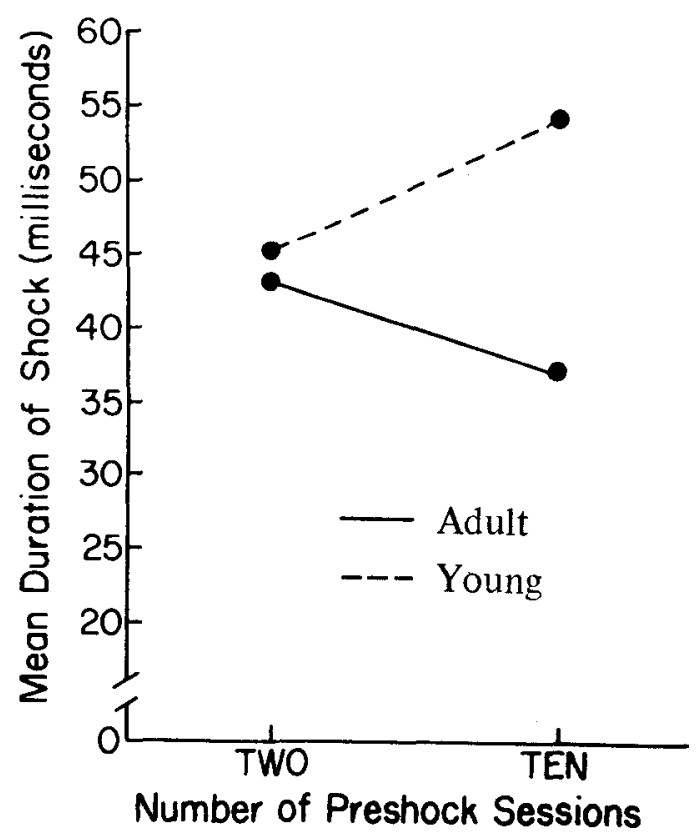

Figure 1. Mean total duration of shock (in milliseconds) received on the shock day as a function of age and the number of preshock sessions.

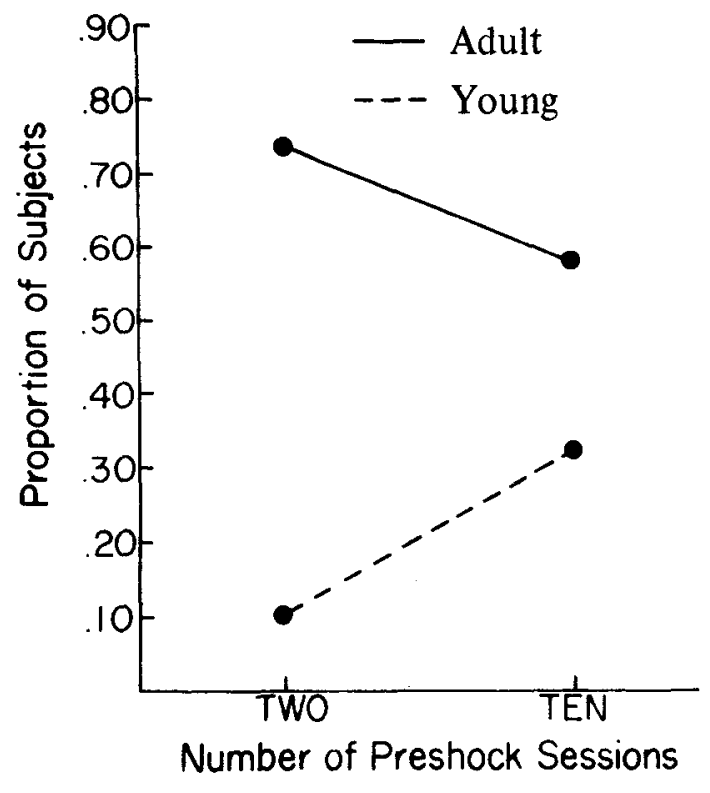

Figure 2. Mean proportion of subjects that stopped responding for $\mathbf{2 0} \mathrm{min}$ during the shock session as a function of age and the number of preshock sessions.

Preshock Sessions, $F=55.9$, $\mathrm{df}=1 / 72, \mathrm{p}<.01$ ). No other interactions were significant $(p>.05)$.

Shock Session

Figure 1 shows the mean total duration of shock received as a function of age and the number of preshock sessions. This total was obtained by summing the durations of individual shocks for each subject. Young rats received significantly more shock than did adults $(\mathrm{F}=4.3 \mathrm{df}=1 / 72, \mathrm{p}<.05)$. While overtraining ( 500 vs. 100 reinforced trials) increased the amount of shock received by the young, it reduced the amount of shock received by the adults (significant Age by Overtraining interaction, $\mathrm{F}=4.1 \mathrm{df}=1 / 72, \mathrm{p}<.05$ ).

In Figure 2 can be seen the proportion of subjects that stopped responding for $20 \mathrm{~min}$ during the shock session. In order to test for the age interaction, the frequency scores were converted by assigning each subject that stopped responding a score of one and each subject that did not stop a score of zero. An analysis of variance indicated that a significantly greater number of adults than of young stopped responding $(F=19.3$, $\mathrm{df}=1 / 72, \mathrm{p}<.01)$. The number of preshock sessions did not influence this measure $(F<1)$. Although the Age by Overtraining interaction appeared similar to that obtained with the amount-of-shock measure, it was not significant $(F=3.4, d f=1 / 72, p>.05)$.

There was a significant increase in session length for both age groups between the last preshock session and the shock session $(F=261.2, \quad d f=1 / 72, p<.01)$. However, this increase was greater for the adults $(\overline{\mathrm{X}}=7.8$ vs. $45.7 \mathrm{~min})$ than for the young $(\overrightarrow{\mathrm{X}}=11.3 \mathrm{vs}$. $29.0 \mathrm{~min} ;$ Age by Session interaction, $F=34.1$, $\mathrm{df}=1 / 72, \mathrm{p}<.01$ ). Session length during the extinction 


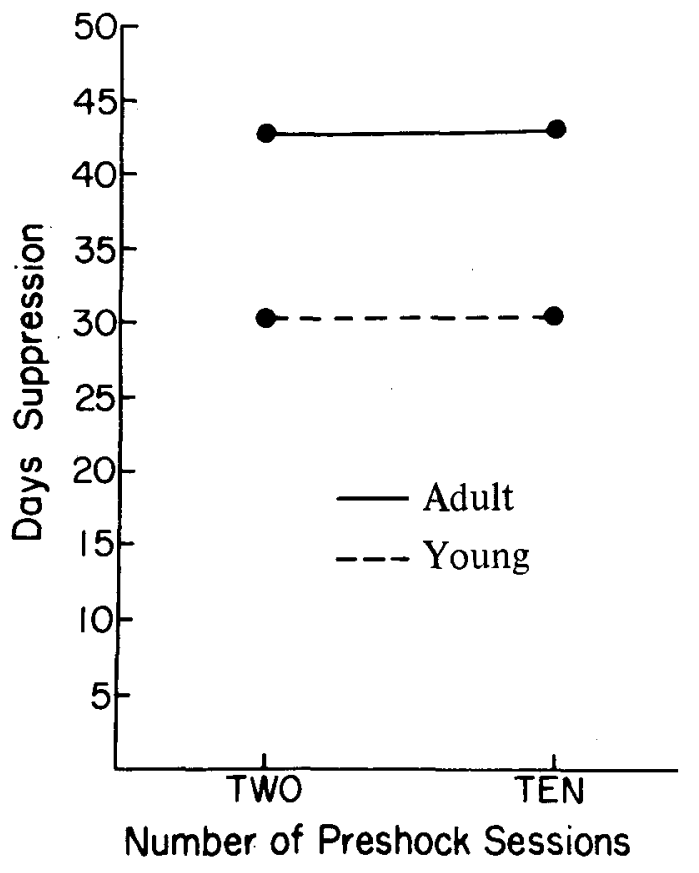

Figure 3. Mean number of postshock sessions during which subjects showed partial or complete response suppression in the shock arm as a function of age and the number $f$ preshock sessions.

session was not a function of the number of preshock sessions $(p>.05)$. The Age by Number of Preshock Sessions interaction was not significant $(\mathrm{F}<1)$.

The mean duration of each shock was $20 \mathrm{msec}$ for adults and $22 \mathrm{msec}$ for the young. Duration of shock was not a function of age or of overtraining (all $\mathrm{F}<1$ ).

\section{Postshock Sessions}

A significantly greater proportion of the adults than of the young received 50 postshock sessions (.66 vs. .16; $\left.\chi^{2}=19.6, \mathrm{df}=1, \mathrm{p}<.01\right)$. Separate analyses were performed with the adults and the young to examine the effects of overtraining. However, the proportion of subjects receiving 50 sessions was not a function of the number of preshock sessions (both $\chi^{2}<1$ ).

Analyses of the session-length data over the first eight postshock sessions indicated that while the adults started out with longer session lengths $(\overline{\mathrm{X}}=14.6$ vs. $11.6 \mathrm{~min})$, their times decreased more than those of the young over sessions so that by the fourth they were running faster (age, $\mathrm{F}=6.9$, df $=1 / 72, \mathrm{p}<.01$; postshock sessions, $\mathrm{F}=18.4, \quad \mathrm{df}=71504, \quad \mathrm{p}<.01 ; \quad$ Age by Postshock Sessions, $\quad F=12.7, \quad d f=7 / 504, \quad p<.01$ ). Although subjects in the 10-day groups started out with shorter session lengths than those in the 2-day groups $(F=7.9$, $\mathrm{df}=1 / 72, p<.01$ ), this difference disappeared by the sixth postshock session (Overtraining by Postshock Sessions, $F=3.05, \mathrm{df}=7 / 504, \mathrm{p}<.01)$.

Recovery scores can be seen in Figure 3. The suppressive effects of punishment were greater for the adult than for the young rats, with the young showing complete recovery 12.5 sessions sooner $(F=19.1$, $\mathrm{df}=1 / 72, \mathrm{p}<.01)$. Recovery scores were unaffected by the number of preshock sessions $(F<1)$. The Age by Number of Preshock Sessions interaction was also not significant $(\mathrm{F}<1)$.

\section{DISCUSSION}

The finding that young rats required a greater amount of shock than did adults in order to produce complete suppression supports the position that young rats have greater difficulty than older rats in inhibiting a response. This age difference was consistent with the results from previous developmental passive avoidance studies in which young rats required a greater number of shocks to suppression (Riccio, Rohrbaugh, \& Hodges, 1968; Riccio \& Schulenburg, 1969). However, this result was not consistent with that found in a previous punishment study (Ernst, 1970) in which there was not a significant difference between adult and young rats with the total-amount-of-shock measure. This may have occurred because the young rats in the previous study were slightly older at the time of shock. It may also have been a function of the different rats used in the two studies (Long-Evans hooded from a commercial supplier vs. Washington State University hooded in the present study), particularly since there is evidence for strain differences in rats in the effects of punishment with an amount-of-shock-to-suppression measure (Storms, Boroczi, \& Broen, 1963).

An additional concern with the amount-of-shock result is whether young rats received more shock because they were physically less capable of withdrawing from shock. This does not seem likely because the mean-duration-of-each-shock measure was not influenced by age.

The overtraining effect found for the adult rats with the amount-of-shock measure and suggested by the proportion-of-subjects-that-stopped-responding measure indicated that additional reinforced trials made their response pattern less resistant to the effects of punishment. This overtraining effect was consistent with that found with adult rats in the previous response-strength punishment studies (Karsh, 1962; Lawson \& Born, 1964; Miller, 1960). More specifically, it agreed with the results of Born (1967) who found that overtraining decreased the amount of shock received by adult rats.

A different relationship emerged between response strength and the amount of shock received by the young rats. Additional training appeared to strengthen their response pattern and make it more resistant to the effects of punishment, a finding which was consistent with the original theoretical prediction and also with the effect found in children (Karsh \& Williams, 1964).

The different relationship found between response 
strength and punishment for the two age groups suggests that the previously mentioned conflict between the findings with children and adult rats may have been due to developmental rather than species differences. This Age by Overtraining interaction is similar to another Developmental by Overtraining interaction found in a study of discrimination learning with children (Gollin, 1964). In that study, overtraining improved-reversal learning in older children but made reversal more difficult in younger children. The effect found with older children was similar to that found with adult rats in the present study, while the effect found with the younger children was similar to that found with the young rats. While the comparison of these results may seem tenuous, both studies involved the use of overtraining trials, subjects of different ages, and the modification of a positively reinforced response pattern by an aversive consequence-in one case shock and in the other case nonreinforcement. This similar Age by Overtraining interaction may suggest a common basis in rats and humans for the developmental processes that underlie the strengthening of a response pattern or the modification of a response pattern once it is established.

The results of the present study suggest that the process of strengthening a response pattern proceeds at different rates for adult than for young rats. Since there is a curvilinear relationship between response strength and the suppressive effects of punishment (Born, 1967; Lawson \& Born, 1964), it is possible that the Age interaction reflected different points on that curve. More specifically, for the young, response strength may have been increasing even after 10 sessions (the ascending portion of the curve), whereas for the adults, 10 sessions may have represented overtraining, and therefore this adult group was on the descending portion of the curve. However, the question remains as to what factors might account for this age difference in the rate at which a response pattern is strengthened and its subsequent resistance to modification by punishment.

Two possible interpretations for this Age interaction will now be examined. Since there have been no extensive analyses of the factors that influence the overtraining-punishment effect, these interpretations have been generated from studies of the overtraining-extinction effect with adult rats (Birch, 1961; Ratliff \& Ratliff, 1971; Sperling, 1965; Traupmann, 1972). This extinction effect is nearly identical to that found in the punishment research; that is, overtraining typically makes a response less resistant to extinction. It is assumed that the factors found to influence the overtraining-extinction effect may also be relevant to the overtraining-punishment effect because of the similarity between extinction and punishment (Wagner, 1969).

The first interpretation focuses on the importance of external and internal cues in the building of a response pattern. There is evidence to support the hypothesis that overtraining tends to transfer control of responding from external to internal cues and that internally controlled responding is less resistant to extinction (Likely \& Schnitzer, 1968). The application of this hypothesis to this study would suggest that with adult rats overtraining produced this change from external to internal control, and therefore they showed the usual overtraining effect. However, in the young rats, the process of internalization of control occurred more slowly than in the adults, and therefore for the young rats in the 10 -session condition responding was still under the control of external cues. One would predict that with additional training, the change from external to internal control would occur and the young would then show the same overtraining effect found with adults.

A second interpretation for the observed Age by Overtraining interaction is based on research which has suggested that overtraining results in a greater role for conditioned frustration as compared to incentive motivation (Barnes and Tombaugh, 1970; Birch, 1961; Clifford, 1968). The application of this interpretation to the present results would suggest that conditioned frustration did not develop as rapidly in young rats as in adults, and therefore the young did not show the overtraining effect after 10 sessions. One would predict that this effect would be found in young rats if one increased frustration, and one way of doing this would be to provide additional training.

Regardless of the interpretation of the Age by Overtraining interaction, a major question concerning the relationship between this finding and the previous developmental punishment research remains. A frequently used measure in the passive avoidance studies has been the number of shocks to suppression. Since age differences were found in this study between response strength and the amount-of-shock-to-suppression measure, it is very possible that the results of the passive avoidance studies using this measure were influenced by age differences in response strength. Since the present study did not use the other suppression measure common to the passive avoidance research-latency to responding after one shock-it is difficult to determine whether the present results relate to those studies.

The overall age difference found with the subjects-that-stopped-responding measure suggested that shock had greater impact on the adult rats. One possible interpretation of this age difference is that shock was more aversive for the adults. However, this interpretation would disagree with the conclusion of Campbell (1967) that intermediate shock levels were equally aversive for adult and young rats. Another interpretation is that the additional deprivation during shock led to greater deprivation for the young rats and therefore fewer of them stopped responding during the shock session.

The age difference found with the sessions-to-recovery measure strongly supported the position that young rats 
are less competent in a task requiring the inhibition of a response-they were responding at the preshock level 12.5 sessions sooner than the adults. These results replicate those in a previous developmental punishment study (Ernst, 1972).

Since the recovery data were not affected by the response-strength factor for either the adult or young rats, this strongly suggests that the age difference in recovery was not influenced by age differences in response strength. By eliminating this as a possible interpretation, the present study provides even stronger support for the position that the age differences in recovery found in this study and the previous one (Enst, 1972) were a function of a differential ability to inhibit a response. The question remains, however, as to why overtraining affected the amount-of-shockto-suppression measure but not the recovery measure. One possible interpretation is that differences in response strength were compensated for during the shock session; that is, subjects with a weaker response pattern received less shock than those with a stronger response pattern. Therefore, recovery would have started from a nearly equivalent baseline. Furthermore, the differential outcome with these two suppression measures is not unusual since Ernst (1972) had found a difference between these two measures with both age and shock-intensity variables.

While the recovery data support the position that young rats are inferior to adults in a task requiring the inhibition of a response, alternative explanations should be considered. The first interpretation is that the young rats were more deprived and this contributed to their faster recovery. However, subjects could obtain the limit of reinforcements without responding in the shock arm and other research has shown that recovery from punishment is not influenced by level of deprivation (Boroczi, Storms, and Broen, 1964). A second interpretation is that inferior retention in young rats contributed to faster recovery. Although there is a substantial amount of evidence for inferior retention in young rats (Campbell \& Spear, 1972), these differences are typically not found with young rats as old as the ones used in this experiment at the time of shock. Moreover, Ernst (1972) used a 25-day retention interval after punishment and found no evidence for greater memory loss in the young. A third interpretation is that the responding of the young rats was less suppressed during shock and this contributed to faster recovery. However, young rats received more shock during the shock session.

Session-length data from the preshock sessions indicated that the young rats took longer than the adults to complete these sessions. This age difference replicates a previous finding (Ernst, 1972), and it may have been a function of slightly greater deprivation for the adults. Support for this interpretation comes from unpublished research which has shown that increased deprivation decreased session length. Moreover, observation of subjects while running indicated that young rats moved around the apparatus more slowly than the adults. Prior to the shock session, subjects in the 10 -session condition were responding faster than those in the 2-session condition. Since session length decreased over sessions, the difference between the 2 - and 10-session groups probably reflected this sessions decrement.

In summary, the results from this study demonstrate that the relationship between overtraining and the suppressive effects of punishment is influenced by the age of the subjects. This Age by Overtraining interaction suggests that response strength may have been an important factor in some of the previous developmental passive avoidance research. It also suggests that the conflict in the overtraining-punishment research between findings with adult rats and children may have been due to developmental rather than to species differences. Since the age-overtraining effect was similar to one found previously with reversal learning in children, this also suggests that there is a common developmental process in rats and humans for the way in which a response pattern is strengthened and/or disrupted by an aversive consequence. In addition, the obtained age differences with the amount-of-shock and sessions-to-recovery measures provide further support for the position that young rats are inferior to adults in the inhibition of a response. The failure to find a relationship between overtraining and recovery strengthens the inhibition interpretation of the age differences in recovery.

\section{REFERENCES}

Barnes, W., \& Tombaugh, T. N. Effects of sucrose rewards on the overtraining extinction effect. Journal of Experimental Psychology, 1970, 86, 355-359.

Birch, D. A. A motivational interpretation of extinction. In M. Jones (Ed.), Nebraska symposium on motivation, Lincoln: University of Nebraska Press, 1961. Pp. 174-197.

Borm, D. G. Resistance of a free operant to extinction and suppression with punishment as a function of amount of training. Psychonomic Science, 1967, 8, 21-22.

Boroczi, G., Storms, L. H., \& Broen, W. E. Response suppression and recovery of responding at different deprivation levels as functions of intensity and duration of punishment. Journal of Comparative and Physiological Psychology, 1964, 58, 456-460.

Campbell, B. A. Developmental studies of learning and motivation in infraprimate mammals. In $H$. W. Stevenson, $E$. H. Hess, and H. L. Rheingold (Eds.), Early behavior: Comparative and developmental approaches. New York: Wiley, 1967

Campbell, B. A., Riccio, D. C., \& Rohrbaugh, M. Ontogenesis of learning and memory: Research and theory. In M. E. Meyer (Ed.), Second western symposium on learning: Early learning. Bellingham, Washington: Western Washington State College. 1971. Pp. 76-109.

Campbell, B. A., \& Spear. N. E. Ontogeny of memory. Psy chological Review, 1972, 79, 215-236.

Clifford, T, Runway length and the failure of expected rewards: The O.E.E. Canadian Joumal of Psychology, 1968, 22, 417-426.

Ernst, A. J. Developmental differences in the suppressive effects of punishment as a function of shock intensity and retention period. Unpublished doctoral dissertation. University of Colorado, 1970.

Ernst. A. J. Developmental differences in the suppressive effects of punishment. Journal of Comparative and Physiological Psychology, 1972, 79, 510-516.

Feigley, D. A., \& Spear, N. E. Effect of age and punishment condition on long-term retention by the rat of active-and 
passive-avoidance learning. Journal of Comparative and Physiological Psychology, 1970, 73, 515-526.

Gollin, E. S. Reversal learning and conditional discrimination in children. Joumal of Comparative and Physiological Psychology, 1964, 58, 441-445.

Hull, C. L. Principles of behavior. New York: Appleton-Century-Crofts, 1943.

Karsh, E. B. Effects of number of rewarded trials and intensity of punishment on running speed. Journal of Comparative and Physiological Psychology, 1962, 55, 44-51.

Karsh, E. B., \& Williams, J. P. Punishment and reward in children's instrumental leaming. Psychonomic Science, 1964, 1, 359-360.

Lawson, R., \& Born, D. G. Recovery from punishment as a function of number of pre-punishment reinforcements. Psy ch onomic Science, 1964, 1, 269-270.

Likely, D., \& Schnitzer, S. B. Dependence of the overtraining extinction effect on attention to runway cues. Quarterly Journal of Experimental Psychology, 1968, 20, 193-196.

Miller, N. E. Learning resistance to pain and fear: Effects of overlearning, exposure, and rewarded exposure in context. Journal of Experimental Psychology, 1960, 60, 137-145.

Moorcroft, W. H., Lytle, L. D., \& Campbell, B. A. Ontogeny of starvation induced behavioral arousal in the rat. Journal of Comparative and Physiological Psychology, 1971, 75, 59-67.

Ratliff, R. G., \& Ratliff, A. R. Runway acquisition and extinction as a joint function of magnitude of reward and percentage of rewarded acquisition trials. Learning and Motivation, 1971, 2, 289-295.

Riccio, D. C., \& Marrazo, M. J. Effects of punishing active avoidance in young and adult rats. Journal of Comparative and Physiological Psychology, 1972, 79, 453-458.

Riccio, D. C., Rohrbaugh, M., \& Hodges, L. A. Developmental aspects of passive and active avoidance learning in rats. Developmental Psychobiology, 1968, 1, 108-111.

Riccio, D. C., \& Schulenburg, C. J. Age related deficits in the acquisition of a passive avoidance response. Canadian Journal of Psychology, 1969, 23, 429-437.

Schulenburg, C. J., Riccio, D. C., \& Stikes, E. R. Acquisition and retention of a passive avoidance response as a function of age in rats. Journal of Comparative and Physiological Psychology, $1971,74,75-83$.

Sperling, S. E. Reversal learning and resistance to extinction: A review of the rat literature. Psychological Bulletin, 1965, 63, 281-297.

Storms, L. H., Boroczi, G., \& Broen, W. E. Effects of punishment as a function of strain of rat and duration of shock. Journal of Comparative and Physiological Psychology, 1963, 56, 1022-1026.

Traupman, K. L. Drive, reward, and training parameters, and the overlearning extinction effect (OEE). Learning and Motivation, 1972, 3, 359-368.

Wagner, A. R. Frustrative nonreward: A variety of punishment. In. B. A. Campbell and R. M. Church (Ed.), Punishment and aversive behavior. New York: Appleton-Century-Crofts, 1969. Pp. 157-181.

(Received for publication April 11, 1974; accepted September $5,1974$. ) 